\title{
Periódico eletrônico Informação \& Sociedade: \\ Estudos - impactos no contexto da comunicação cientifica
}

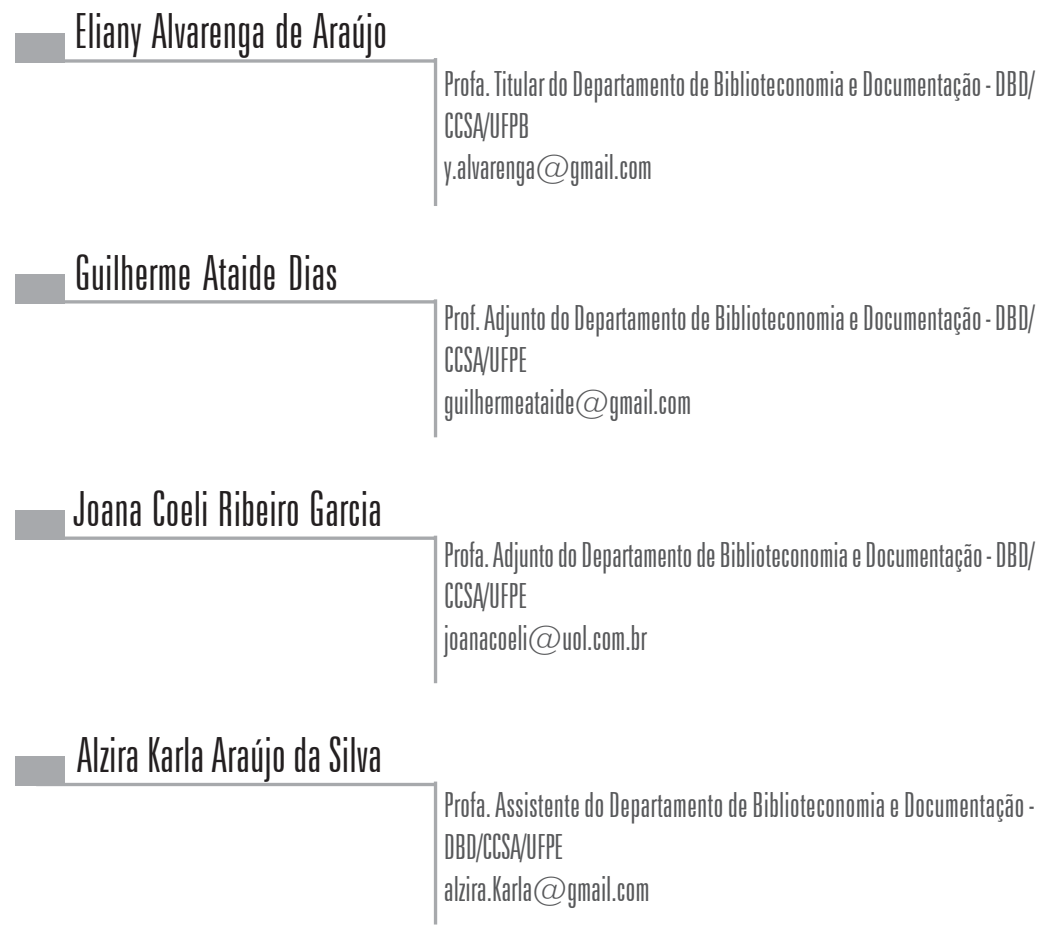

Analisa os impactos provocados pelo acesso e uso do periódico Informação \& Sociedade: Estudos, em versão eletrônica. Os dados foram coletados junto à comunidade de leitores, avaliadores e autores do referido periódico, em março de 2006, utilizando-se questionário semi-estruturado enviado via correio eletrônico. Os impactos positivos mais citados são: maior agilidade e amplitude no acesso, uso, recuperação, divulgação da informação; diminuição da necessidade de acesso físico à biblioteca; ampliação da produção intelectual. Os impactos negativos são: site do periódico fora do ar; dificuldades na recuperação da informação devido a erros de representação temática e programação visual do periódico.

Palavras-chave: Periódicos científicos eletrônicos - impactos; Informação impacto; Comunicação científica - periódicos científicos eletrônicos 


\section{Introdução}

O conceito de periódico científico eletrônico é atribuído a Sondak e Scwartz (1973), ao descreverem as características de um periódico científico paperless. Eles citam as vantagens inerentes a um sistema de divulgação sem uso do papel, tais como: economia de tempo, de recursos financeiros e de espaço. De forma profética, eles comentam que o sucesso de um periódico paperless está ligado à aceitação desse recurso pelos usuários, destacando que estar disponível, não significa que uma tecnologia será empregada; o sucesso é determinado pelos benefícios percebidos pelos usuários, não pela adoção da tecnologia.

Concorda-se de forma incisiva com a afirmaç̧ão de King e Tenopir ( 1998 , p. 32) de que "a questão não é mais se os periódicos científicos vão estar disponíveis no formato eletrônico, mas quando, e se a versão eletrônica pode ou não substituir a versão em formato impresso". Tal colocação tem se concretizado na área da ciência da informação através da criação de versão eletrônica dos periódicos científicos editados pela mesma. Assim, os periódicos científicos Encontros Bibli (QUALIS Nacional/A, periodicidade semestral, publicado desde 1996) e Datagramazero (QUALIS Nacional/A periodicidade bimensal, publicado desde 1998) já nasceram e são disponibilizados apenas na versão eletrônica. Por outro lado periódicos tradicionais da área, tais como Ciência da informação (QUALIS Nacional/A, periodicidade semestral, publicado desde 197I); Transinformação (QUALIS Nacional/A, periodicidade semestral, publicado desde 1989) e Perspectivas em Ciência da Informação (QUALIS Nacional/A, periodicidade semestral, publicado desde 1996, em substituição à Revista da Escola de Biblioteconomia da UFMG) criaram versões eletrônicas na década de 90 consolidando, assim, uma tendência mundial em termos de comunicação científica no contexto da WEB.

Baseados na necessidade de avaliar o impacto deste periódico científico eletrônico visando reformulações que viessem a dinamizar o acesso e uso da informação científica e tecnológica disponibilizada através do mesmo, foram formulados os seguintes questionamentos a comunidades de usuários de Informação \& Sociedade - I\&S - (autores, leitores e avaliadores): a) Considerando as atividades de ensino, pesquisa e extensão, em que campo de atuação I\&S é mais útil? b) Qual formato - PDF ou HTML - seria o preferido? c) Existem dificuldades no uso da ferramenta de busca? d) Que barreiras são encontradas ao usar I\&S? Estes questionamentos direcionaram as análises apresentadas neste artigo.

\section{Historiando Informação \& Sociedade: Estudos}

Informação \& Sociedade: Estudos - I\&S - é um periódico científico criado pelo Curso de Mestrado em Biblioteconomia, da Universidade Federal da Paraíba - UFPB, em 199I, como um veículo de comunicação científica que pretendia divulgar a produção de pesquisadores da área da ciência da informação e áreas correlatas. Para tanto, procurou fortalecer sua pertinência temática na área, sua qualidade editorial através do estabelecimento de normas editoriais e periodicidade regular. Através destas ações I\&S conseguiu, nestes I 5 anos de existência, se consolidar como um canal de comunicação científica 
competente e vem ampliando sua atuação e, assim, vem alcançando o reconhecimento da comunidade da área de ciência da informação. Um exemplo desse reconhecimento caracteriza-se através da classificação na base QUALIS, da CAPES, como periódico nacional - categoria A.

Em 2000, I\&S disponibilizou todos os seus números, com texto completo, no site acessível a partir da URL http:// www.informacaoesociedade.ufpb.br, concretizando sua versão eletrônica. Em 2003 sobrevêm dificuldades orçamentárias, impossibilitando a sua publicação na versão impressa. Nos anos seguintes I\&S é indexada pela Base de Dados Bibliográfica em Ciências Sociales y Humanidades (CLASE), pelo Portal da CAPES, INFOBILA e LATINDEX. Em 2005 o Centro de Ciências Sociais Aplicadas - CCSA/UFPB, do qual o então Curso de Mestrado em Biblioteconomia, agora Curso de Mestrado em Ciência da Informação da UFPB faz parte, destinou verba para a publicação impressa dos números de 2003 a 2005, permitindo a continuidade da publicação impressa, além da eletrônica. Ainda neste período, considerando sugestões dos usuários e dos docentes do Departamento de Biblioteconomia e Documentação da UFPB e objetivando torná-la mais acessível aos seus usuários, são realizadas alterações na versão eletrônica de I\&S, constantes de: remoção do uso da tecnologia flash; recuperação dos expedientes em todos os números; criação de versões em formato texto de todos os arquivos existentes no formato PDF; criação de metadados Dublin Core/RDF para referenciar os artigos; padronização na nomenclatura dos arquivos; criação de ferramenta de busca (EUREKA!) com tecnologias relacionadas à web semântica.

Em maio de 2006 foi iniciado o processo de implantação do Sistema Eletrônico de Editoração de Revistas - SEER -, para que a gestão do processo de produção ocorra também por meio eletrônico. A instalação deste sistema foi realizada em um servidor departamental, estando no processo de migração os arquivos desde o primeiro número em 200 I , até o atual, realizando cadastro de avaliadores, alimentando a mala direta com e-mails dos leitores e autores de I\&S e todas as fases iniciais para que se possa usar, efetivamente, o SEER. Ainda nesse ano a versão eletrônica de I\&S obteve o seu número de ISSN, a qual usava até então o da versão impressa. Iniciou-se, também, a inclusão, em todos artigos nos formatos PDF e HTML, a legenda bibliográfica, para garantir que o artigo seja identificado, uma vez impresso. Através destas ações I\&S tem buscado seu espaço enquanto canal de comunicação científica ágil e eficaz no contexto da ciência da informação desenvolvida no país.

\section{Impacto da informação: abordagem conceitual}

Conforme Meadows e Yuan (1997), o termo impacto tem múltiplos significados, mas, tratando-se do impacto da informação, existe um ponto comum de compreensão que ele ocorre na base de conhecimento do receptor/usuário de informação. Assim, podemos considerar três tipos de impacto da informação:

- O impacto é uma mudança, ou a natureza ou magnitude da mudança na base de conhecimento do receptor/usuário de informação. $\bigcirc$ impacto é uma mudança no comportamento do receptor/usuário de informação presente no momento da tomada de decisão, baseada na mudança que ocorre na base de conhecimento do mesmo; 
- O impacto é uma mudança na forma em que o receptor/usuário se comporta no momento da busca à informação e a partir de resultados preliminares;

- O impacto é uma mudança no nível organizacional ou social causado, em grande parte, pelo acesso/uso de informação.

A análise do texto de Meadows e Yuan (1997) possibilita duas considerações. A primeira é que a definição de impacto passa pela noção de mudança na estrutura de conhecimento do usuário de informação. A segunda consideração considera que a alta taxa de subjetividade nas variáveis que compõem o fenômeno impacto da informação gera incertezas quase intransponíveis para sua análise, em termos científicos.

Menou ( 1999 ) estudou, de forma profunda, o tema - impacto de informação. Para este autor o termo impacto pode ser entendido como mudanças nas habilidades dos atores no tratamento de seus problemas; ou seja, impacto é a mudança na habilidade das pessoas em satisfazer suas necessidades advindas do uso de recurso(s) de informação. O termo impacto refere-se a uma variedade de fenômenos distribuídos em um contínuo que vai desde a mera novidade aparente, a transformações de comportamento a nível individual ou social. De forma mais específica podemos considerar que:

[...] o impacto deveria se restringir a mudanças substantivas e duradouras que ocorrem na base de conhecimento, no comportamento, organização ou eficácia dos indivíduos, instituições ou sociedade. Na medida em que a sustentabilidade é um atributo primário da definição acima, poderíamos restringir ainda mais o impacto às mudanças nas habilidades dos atores no tratamento de seus problemas. [...] Neste ponto impacto é bastante similar à aprendizagem (MENOU, 1999, p. 8).

Considerando esta definição podemos visualizar uma variedade de fenômenos distribuídos em um contínuo, que vai da mera aparência até o nível do aprendizado. Assim, conforme Menou (1999), na extremidade mais baixa do espectro, poder-se-ia dizer que existe um impacto, pois certo número de pessoas ou organizações estão acessando informação(ões). O próximo aspecto a ser observado é o crescimento do número de usuários devido a um maior uso de produtos e serviços de informação. A partir disso podemos ver mudanças no padrão de uso. Seguindo este nível, podemos considerar os efeitos resultantes do acesso/ uso de informação. Assim, uma vez que as ações consideradas resultantes das mudanças acima mencionadas produzem efeitos, estes podem, por seu lado, induzir uma série subseqüente de mudanças, isto é a adaptação, a adoção e a institucionalização daquelas alterações iniciais. Conforme Menou ( 1999), neste momento, finalmente estaremos entrando na área que deveria ser conhecida como de impacto propriamente dita. Mas este autor alerta que, ao afirmar que o impacto é representado pelo aspecto citado anteriormente, não quer dizer que outros aspectos devam ser desconsiderados. Ao contrário, todos estes aspectos possibilitam o rastreamento dos verdadeiros impactos. 


\section{Abordagem metodológica}

Conforme ressaltado, Menou (1999) buscou superar as dificuldades teórico-metodológicas do impacto da informação, relatando em diferentes textos, pesquisas sobre a temática e suas abordagens metodológicas. Assim, os estudos sobre impacto baseiam-se em comparar uma situação inicial, antes do acesso/uso de determinada(s) informação(ões) e a situação em algum momento posterior. Infelizmente, conforme este autor, devemos admitir que o conhecimento real da situação anterior é, geralmente, superficial. A situação posterior também é analisada com falhas, pois se estrutura por meio de lembranças dos usuários.

Apesar das falhas do método antes-depois, Menou (1999, p. 12) o considera válido, mas adverte que, para melhor uso: "os estudos de impacto deveriam desenvolver um esforço significativo na investigação cuidadosa da situação inicial, anterior àquela em que o uso de informação se torna lugar comum". $\bigcirc$ autor salienta que a abordagem antes-depois aponta quais mudanças ocorreram, mas dirão pouco sobre como e porque ocorreram. Para atender tais aspectos, de forma satisfatória, devemos utilizar a técnica de observação. Outros métodos citados por este autor são os seguintes: método antropológico e pesquisa-ação. Em termos de tipo de pesquisa, Menou ( 1999) cita o levantamento como o mais adequado. Um último ponto indicado por ele, é que as pesquisas sobre impacto de informação devem se orientar para o propósito de compreender o que ocorre e não oferecer resultados rápidos e imprecisos em apoio a teorias e planos predeterminados. Estas considerações respaldam nossas decisões metodológicas. Assim o estudo do(s) impacto(s) da informação não é uma tarefa fácil, pois, por um lado, o tema é de difícil caracterização conceitual e metodológica e, por outro lado, este tema ainda é recente no contexto dos estudos de uso e impactos da informação. A partir desta consideração, apresentamos a seguir a metodologia desenvolvida para a efetivação dessa pesquisa.

\subsection{Delimitação do campo de pesquisa}

O campo de pesquisa foi delimitado em torno da comunidade de usuários de I\&S. Vale salientar que esta comunidade está classificada a partir dos seguintes papéis sociais: autores, leitores e avaliadores. Foram enviados 400 ' questionários via e-mail. Obtivemos um retorno de 52 e-mails válidos, caracterizando uma amostragem de 13,0\% do universo. Vale salientar que este percentual, apesar de reduzido em termos numéricos se for considerado o universo citado, representou uma rica amostra de reflexões sobre a temática estudada. Tal consideração evidencia a abordagem qualitativa assumida por essa pesquisa, no sentido de que, conforme coloca Triviños (1987) a pesquisa aqui relatada tem o ambiente natural como fonte dos dados; é descritiva, pois tenta captar as relações, as mudanças e as conseqüências do fenômeno estudado; preocupa-se com os processos vivenciados pelos pesquisados; utilizase da indução para analisar os dados e tem no significado das falas dos pesquisados sua fonte principal de interpretação dos dados. Diante destas considerações a quantificação da amostragem (13\%) não foi considerada reduzida, pois a mesma representa sujeitos cognitivos ativos e experientes na
Este número inclui a comunidade de usuários representada pelos endereços eletrônicos da mala direta de I\&S. 
temática estudada, ou seja, os sujeitos que responderam ao questionário são aqueles que mais se relacionam com a problemática estudada, o que torna suas colocações extremamente significativas para o estudo em questão.

\subsection{Etapas e técnicas de pesquisa}

Inicialmente foi delimitado o problema da pesquisa em torno da identificação e análise dos impactos percebidos pela comunidade-usuária de I\&S em relação ao uso de periódicos eletrônicos no contexto da comunicação científica. Num segundo momento, foi estruturado o instrumento de pesquisa - questionário via e-mail. Vale salientar que foi dado o prazo de uma semana para retorno. Conforme Simsek ( 1999) o survey via e-mail é uma forma barata e com o desenvolvimento dos computadores torna-se das mais rápidas de conseguir amostra neste tipo de pesquisa, sendo relativamente recente seu uso. Ademais, quando comparado às formas tradicionais de survey, como entrevista pessoal e questionário via correios, mantém as seguintes vantagens: altíssimas flexibilidades geográficas e de tempo; conveniência do preenchimento e a manutenção do anonimato como altas; e facilita o contato inicial com o respondente e o retorno da resposta. Estas razões justificam a escolha pela técnica de pesquisa.

Encerrado o período estabelecido, iniciamos a organização dos dados, para o que foi utilizado o Statistical Package for the Social Science - SPSS - na tabulação das questões fechadas, obtendo percentuais simples. $\mathrm{Na}$ interpretação das questões abertas, foi estabelecida uma categorização temática visando adotar a técnica de análise de conteúdo como auxiliar na análise dos dados.

\section{Análise e interpretação dos dados 5.1 Identificaçãa da comunidade pesquisada}

Em termos da formação básica da comunidade tem-se que 57,7\% provêm da área da biblioteconomia. Dentre os pesquisados, 51,9\% têm a titulação de doutor sendo que, destes, 38,5\% tem tal titulação na área da ciência da informação. Em termos do vínculo institucional, tem-se que 80,8\% têm vínculos com universidades. Em relação às atividades nas quais I\&S é mais útil, tem-se que 94,2\% utilizam o periódico para desenvolver atividades de ensino, com destaque para atualização de conteúdo e utilização em sala de aula, e 92,3\% para pesquisa e extensão, com realce para levantamento bibliográfico e produção de textos.

Em termos do perfil de atuação, tem-se que os pesquisados se identificaram da seguinte forma: 40 leitores, 34 autores e 14 avaliadores. Salientamos que o item perfil de atuação junto a I\&S permite classificações simultâneas, o que explica o total de 88 respostas.

\subsection{Impactos da informação: Possiveis mudanças no contexto da comunicação cientifica}

Inicialmente, apresentam-se os elementos que foram citados como fatores de impacto de caráter positivo (acesso, armazenamento, atualização, 
pesquisa, tempo, formatos PDF e HTML) e, num segundo momento, os elementos que foram citados como fatores de impacto de caráter negativo (site fora do ar, representação temática da informação, programação visual e uso da ferramenta de busca).

\subsubsection{Fatores de impactos positivos}

\section{a) Acesso}

O acesso à informação é rápido, amplo e sem limites geográficos, o que provoca um maior uso e geração de informações. Os alunos não têm desculpas do tipo: não tive acesso ao material, pois agora podem ter acesso rápido aos textos completos. Um outro aspecto realmente inovador e que caracteriza impacto é o acesso em casa, ou no trabalho sem a necessidade de ir à biblioteca e sem bibliotecários, enquanto intermediários entre o usuário e a informação.

Nestas falas emergem como expressão-chaves: agilidade, rapidez e amplitude. A partir destas colocações tem-se que atualmente o acesso à informação é realizado de forma rápida em decorrência do uso de tecnologias de informação, o que amplia a recuperação e o uso de informação. Considerando o impacto da informação desenvolvido por Menou (1999), baseado nos conceitos de mudança de comportamento e de aprendizado, fica demarcado um novo comportamento do usuário da informação, ou seja, um usuário que também trabalha em casa (teletrabalho) e que se sente independente, na busca e acesso à informação, em relação a bibliotecas e bibliotecários. Tal independência evidencia outra, a independência da informação em relação ao formato, ou seja, ao realizar acesso e uso de informação o formato (livro, capítulo de livro, artigo de periódico, anais de evento etc) não representa o elemento preponderante, pois a informação, no contexto digital, adquire status em si e não através de algo.

Um aspecto que vale uma análise é a colocação de que o usuário da informação não necessita ir à biblioteca ou não necessita de bibliotecário para localizar a informação. Tal consideração deve estimular os bibliotecários a uma reflexão profunda no sentido de gerar serviços e produtos de informação compatíveis com as necessidades e perfis dos usuários e com formatos variados, ultrapassando o tradicional formato impresso.

\section{b) Armazenamento}

"Posso armazenar e criar estoques de informação - bancos de dados pessoais -, no meu computador e consultar artigos nos arquivos criados pormim".

"Posso enviar aos meus orientandos e usar estoques de informação que estão distantes".

"Posso compartilhar informações. Não necessito possuir fisicamente a informação". 
O sentimento de posse que permeia as falas é um elemento que se destaca. A partir desta compreensão surge a idéia de poder - poder para acessar, armazenar, compartilhar, manipular. Poder para criar de forma mais autônoma. Em termos teóricos e, a partir do conceito de impacto adotado por Menou ( 1 999), temos, sem dúvida alguma, uma mudança de comportamento do usuário da informação, a partir do momento em que o mesmo detém um poder de decisão que antes não possuía.

\section{c) Atualização}

"A atualização dos conteúdos ministrados em sala de aula e dos projetos de pesquisa tem sido possibilitada por meio do uso de periódicos eletrônicos".

"Assim posso acompanhar o que está sendo publicado através de uma literatura geográfica e teoricamente mais atualizada".

As falas apresentadas acima deixam evidente a idéia de monitoramento, que complementa e confirma a percepção anteriormente apresentada, relativa ao poder de decisão do usuário da informação. Assim, o usuário é agora um sujeito ativo no processo de acesso e uso de informação via periódicos eletrônicos, não apenas na função de leitor, mas também como crítico do nível de atualização e abrangência, ou seja, em termos do nível de validade dos conteúdos acessados.

\section{d) Busca}

"O uso de periódicos eletrônicos torna a busca mais fácil e rápida através de mecanismos de busca que otimizam o tempo gasto nesta atividade".

A ação de busca antecede o momento do acesso e do uso, e o destaque acima confirma a idéia de agilidade e rapidez. No entanto a idéia de rapidez, já localizada e comentada no item acesso, faz surgir aqui a racionalidade do tempo a partir do contexto da informação eletrônica.

\section{e) Geração de informação}

"O uso de periódico eletrônico melhora a geração de informação, pois possibilita a obtenção de uma maior quantidade de informações, bem como um 'acesso mais rápido' às mesmas".

"Isto tem nos auxiliado a gerar informações e textos à distância em conjunto com outros pesquisadores, o que nos possibilita 'ampliar quantitativa e qualitativamente a nossa produção intelectual'".

Nestas falas as expressões em destaque: o acesso e a busca realizados de forma rápida, bem como a produção intelectual dá a idéia de produtividade que, por sua vez, remete a um importante item vivenciado pelos sujeitos pesquisados - publique ou pereça. Este lema 
da comunidade acadêmica se fortalece a partir do uso de periódicos eletrônicos. Aqui não surge, em sentido amplo, impactos enquanto mudança de comportamento, mas o fortalecimento de um comportamento ou tradição. Mas pode-se considerar também, em sentido específico, um impacto na forma como tal tradição se mantém, pois a mesma se perpetua através das tecnologias de informação, assumindo características de agilidade e de rapidez.

\section{f) Pesquisa}

Foi solicitado aos sujeitos da pesquisa que indicassem dentre os campos de atuação - ensino, pesquisa e extensão - aquele(s) em que mais utilizava(m) os periódicos eletrônicos. A atividade de ensino obteve 94,2\%, seguida da atividade de pesquisa (92,3\%). Entretanto nas questões abertas foram obtidas justificativas apenas para o campo de atuação - pesquisa. A este respeito temos as seguintes falas:

"Através do uso de periódicos eletrônicos obtenho maior rapidez e amplitude de conteúdos para minhas pesquisas. Assim faço pesquisa no meu próprio ambiente, acessando diferentes conteúdos e com isto aproveito melhor meu tempo".

As expressão-chaves novamente são: rapidez, agilidade e amplitude de conteúdos. $\bigcirc$ que pode ser caracterizada - tempo -, remetendo-nos para as falas citadas anteriormente no item geração. E, novamente, as idéias de quantidade e qualidade concretizadas por meio da produtividade intelectual dos pesquisados.

\section{g) Tempo}

"O uso de periódicos eletrônicos possibilita a 'agilidade e a otimização de meu tempo', pois 'a informação está acessível o tempo todo'. Assim uso 'em tempo real e aproveito melhor o meu tempo '".

As expressões destacadas se reúnem em torno da noção de tempo, variável presente também nos itens geração e pesquisa. Aliás, a questão do uso racional e eficiente do tempo no contexto digital é um elemento constante e prepondenrante. As citações de agilidade e rapidez se relacionam ao uso do tempo e neste contexto quanto mais rápido, mais tempo se tem para novas produções. Cabe aqui tentar compreender a que se destina uma busca tão intensa pelo tempo e pelo seu uso de maneira eficiente. Para construir tal compreensão deve-se inicialmente trazer um outro conceito, que se relaciona intimamente com o conceito de tempo, qual seja o de velocidade. Este conceito nos permite caracterizar ou adjetivar o tempo no contexto digital. $O$ tempo de que falam os sujeitos pesquisados não é um tempo lento, que demora a passar. Muito pelo contrário ele passa com a velocidade da luz.

Conforme Virílio (1992), a velocidade não é um fenômeno, mas é a relação entre fenômenos. Assim ao aproximar os dois conceitos - tempo e velocidade - percebemos que eles são idênticos e que não existe, no contexto digital, outra realidade, senão a realidade da informação rápida. Neste contexto, 
a informação só tem valor pela rapidez de sua difusão, ou melhor, pela velocidade de geração, acesso e uso. Assim a velocidade é a própria informação no contexto digital. Os sujeitos pesquisados incorporam tal realidade em seus discursos e vivências. No mesmo sentido, há uma velocidade para o descarte do que não interessa e de armazenagem do que será útil, inclusive para usos futuros. O tempo, dessa forma, interfere na velocidade em que as informações devem ser disseminadas.

\section{h) Formatos - PDF e HTML}

"O formato PDF é mais agradável, permite maior mobilidade entre as páginas, melhor leitura, reprodução mais organizada, melhor visualização, facilidade de impressão, seguro para autores, reproduz o formato impresso, disponibiliza arquivo e impressão, mais fácil de ler".

"O formato HTML é legal para fazer leitura na tela do computador, mas o PDF é melhor para arquivar no computador. Penso que seria interessante que os periódicos eletrônicos apresentassem os dois formatos e deixassem que os usuários decidissem de acordo com suas preferências".

As expressões são variadas, mas podem ser reunidas a partir de um único termo - usabilidade -, tanto em termos do PDF, como do HTML. Por usabilidade pode-se compreender a medida de efetividade de uma determinada ferramenta, instrumento ou qualquer artefato humano empregado na realização de uma tarefa específica. Assim, um produto, sob a perspectiva da usabilidade, deve permitir ao usuário realizar uma tarefa, para a qual está destinado, de maneira fácil e eficiente. A partir desta compreensão, o PDF atinge melhores níveis de usabilidade e de impacto positivo, permitindo aos usuários realizar de forma mais eficiente as tarefas a que se propõem.

\subsubsection{Fatores de impactos negativos}

Algumas respostas aos itens indagados constituíram-se em posicionamentos extremamente críticos em decorrência de situações que geram impedimentos nos processos de acesso e de uso de informação. Eles estão apresentados com a denominação de fatores de impactos negativos, pois podem gerar mudanças nas habilidades e no comportamento dos usuários de informação no sentido de afastá-los do uso intensivo e produtivo da mesma.

\section{a) Site fora do ar}

"O site está fora do ar com muita freqüência. Isto dificulta e desanima o uso do mesmo. Deveriam cuidar mais deste aspecto".

Esta situação, ressaltada por aproximadamente 70\% dos pesquisados, não exige maiores esforços de análise e interpretação, pois se relaciona a uma questão de infra-estrutura de equipamentos e de uma política institucional de gerenciamento dos conteúdos digitais disponibilizados. Vale salientar, portanto, a responsabilidade de uma instituição quando disponibiliza tais conteúdos no sentido 
de acompanhar os mesmos, uma vez que estes, de certa forma, evidenciam a competência intelectual da instituição, por um lado, e por outro, o compromisso e o respeito pelos usuários com a qualidade da informação disponibilizada.

\section{b) Representação temática da informação}

"A ausência de lista de palavras-chave gera dificuldades de recuperação da informação que se quer. Tenho dificuldade em usar o sistema de busca para encontrar o que quero".

A representação temática da informação foi sempre um desafio para o mundo da informação representar, de forma conveniente e completa, os conteúdos dos textos e, assim fazendo, auxiliar o usuário da informação na sua busca por conteúdos significativos. A ampliação da disseminação da informação via internet amplia também os problemas seculares relativos à busca e ao acesso a conteúdos significativos para os usuários de informação. Reafirma esta situação o que ocorre no contexto da comunidade de I\&S.

\section{c) Programação visual}

"Acho 'oportuna uma nova programação visual' na revista".

"Falta legenda bibliográfica".

A expressão a ser destacada seria: programação visual, o que nos conduz novamente a usabilidade. Conforme a ISO 924I a usabilidade "é a extensão em que um produto pode ser usado, para alcançar objetivos específicos com eficácia, eficiência e satisfação, em um contexto específico de uso". (BARBOZA et al., 2000, p. I I 8). A usabilidade não existe num produto em si. Ela surge na relação que se estabelece, quando o usuário manipula um produto. Nesse sentido, o contexto de uso, envolve o usuário, a tarefa, o equipamento e o ambiente. Estes elementos determinam a configuração final do produto, bem como o nível de usabilidade que o mesmo apresenta.

Estudos de usabilidade são comuns em pesquisas sobre a interação homem/computador ou homem/conteúdos digitais, que objetivam tornar a relação entre as pessoas e estes contextos mais agradável e produtiva, reduzindo distâncias e gerando satisfação do usuário de informação. Por isso os testes de usabilidade têm sido apontados como instrumentos valiosos para a avaliação de conteúdos digitais. Neste contexto temos outro desafio a ser enfrentado pela editoria de I\&S, uma vez que a atual programação visual tem gerado dificuldades no acesso e uso de informação demandada pelo usuário da informação.

\section{d) Ferramenta de busca}

"Não uso a ferramenta de busca, pois ela recupera muito pouco do que eu quero, assim eu não confio no resultado das buscas'".

"Prefiro ler o sumário da revista e os resumos dos artigos". 
O uso da ferramenta de busca está indicado por 59,6\% dos respondentes, porém chama atenção o grande número que não justifica a utilização (40,4\%). Entre aqueles que o fizeram destacamos "não uso ferramentas de busca e não confio nos resultados". A idéia que fica ressaltada é a de desconfiança no recurso - ferramenta de busca - originando uma crise de credibilidade que leva ao desuso. A esse respeito pode-se fazer uma correlação com o item representação temática da informação, ou seja, o uso reduzido das ferramentas de busca é gerado devido à recuperação de itens pouco representativos em termos de conteúdos informacionais. Aqui há mais um desafio para a editoria da revista, no sentido de melhorar a representação dos conteúdos e, assim, tornar a recuperação de informação via ferramentas de busca mais confiável e produtiva.

\section{Considerações finais}

A análise dos dados permitiu a visualização de fatores de impactos positivos na base de conhecimento, no comportamento e na eficácia dos pesquisados. Tal cenário possibilita que se considere que a comunicação científica pode estar vivenciado significativos impactos em decorrência do uso de periódicos científicos eletrônicos. Confirmando Menou (1999), temos mudanças substantivas na base de conhecimento dos pesquisados decorrentes de mudanças nos comportamentos de busca, acesso, armazenamento e gerenciamento da informação. Este cenário sugere um rico processo de aprendizagem.

Por outro lado foram obtidos também dados sobre fatores de impactos negativos que se relacionam a três temas: site fora do ar, representação temática da informação e programação visual e uso reduzido da ferramenta de busca. Conforme já abordado, estes são os desafios a serem enfrentados e resolvidos no sentido de garantirmos que os impactos positivos sofridos pela comunicação científica em decorrência do uso das novas tecnologias de informação sejam duradouros e construtores de uma realidade de democracia informacional no contexto do periódico Informação\&Sociedade: Estudos. Tal realidade, conseqüentemente, fortalecerá a ciência da informação e áreas correlatas, como uma ação pensada e desenvolvida para toda a sociedade, destacando-se a relação fundamental - sociedade/informação/ciência da informação. Vale salientar ainda que novos padrões de uso da informação em contextos eletrônicos poderão se institucionalizar efetivando assim novas configurações para a comunicação científica. A confirmação ou não desta tese deverá ser feita por meio de novos estudos sobre a temática.

\section{The electronic journal "Informação \& Sociedade: Estudos" - impacts on the context of scientific communication}

This paper analyzes the information impacts caused by the access and use of the electronic journal Informação \& Sociedade: Estudos. A questionnaire, sent to readers peer-reviewers and authors by e-mail in March 2006, was used to collect the research data. The positive impacts mentioned were: more agility in the access, in the use, retrieval and information diffusion; decreased number of physical visits to libraries; increase in intellectual productivity. The 
negative impacts were: journal site not accessible; difficulties in information retrieval due to errors in subject analyses and journal design.

Key-words: Electronic journals-impact; impacts on information ; Scientific communication-Electronic journals.

\section{Referências}

BARBOZA, E; NUNES, E. M. A.; SENA, N. K. Web sites governamentais: Uma esplanada à parte. Ciência da Informação, Brasillia, v. 29, n . 1, p. 118-125, jan./abr. 2000.

DIAS, G. A. Periódicos cientificos eletrônicos brasileiros na área da Ciência da Informação: análise das dinâmicas de acesso e uso. 2003. 1980. (Tese (Doutorado em Ciência da Informação). Universidade de São Paulo, 2003.

HAWKIINS, D. Bibliometrics of eletronic journals of information science. Information Researchs, v. 1, n. 1. Disponivel em http://informationr.net/ir/paper120.html. Acesso em 28 nov. 2001.

KING, D.; TENOPIR, C. A publicação de revistas eletrônicas: economia da produção, distribuiç̧ão e uso. Ciência da Informação, Brasilia, v. 27, n. 2, p. 176182, maio/ago. 1998.

MEADOWS, C.; YUAN, W. Measuring the impact of information: defining the concepts. Information Processing \& Management, v. 3/4, p. 455-477, 1997.

MENOU, M. Impacto da Internet: algumas questões conceituais e metodológicas ou como acertar um alvo atrás da cortina de fumaça. DataGramaZero, n. 0, dez. 1999.

SIMSEK, Zeki. Sample surveys via electronic mail: a comprehensive perspective. Revista de Administração de Empresas, São Paulo, v. 39, n. 1, p. 77-83 jan./ mar. 1999 .

SONDAK, A: SCWARTZ, M. Electronic Publishing of Professional articles: Attitudes of academics and implications for the scholarly communication industry. Journal of The American Society for Information Science, .v. 45, n. 2, p.73-100, 1973.

TRIVIÑOS, Augusto N. S. Introdução à pesquisa em ciências sociais: a pesquisa qualitativa em educação. São Paulo: Atlas, 1987. 175 p.

VIRILIO, Paul. A arte do motor. São Paulo: Papirus, 1992. 